\title{
LA UTILIZACIÓN DE FUENTES EN LA REALIZACIÓN DE DICCIONARIOS: ¿COVARRUBIAS (1611), FUENTE DIRECTA EN LA MICROESTRUCTURA DE FRANCIOSINI (1620)?
}

\author{
José Joaquín Martínez Egido \\ Universidad de Alicante' \\ JJ.Martinez@ua.es
}

\begin{abstract}
Resumen
The development of the lexicographer's task at the very beginning of the Spanish lexicography activity was based on the conveyance of materials from some works to others, as well as on the imposition of some canons in the way of approaching and developing them. In several occasions, the lexicographers have been accused of a lack of originality, even labels as "copy", "plagiarism" or "source" have been used to hold in contempt their works.

The relationship between "Tesoro de la lengua castellana o española" (1960) from Sebastián de Covarrubias and "Vocabulario italiano-español, español-italiano" (1920) from Lorenzo Franciosini can help us to understand the lexicographer's task in that period of the origin and development of the Spanish lexicography, to be exact, with the comparison of their microstructures it can be delimited if the first dictionary is present in the second one and it can also be determined in what way it does.

With this kind of quantifier and detailed analysis we can know the true relationships that exist between the dictionaries. In addition, we can avoid remaining in partial appreciations that tend to become difficult to prove truths.
\end{abstract}

\section{Introducción}

El desarrollo de las primeras obras lexicográficas del español tiene como punto de partida el modelo que impone el primer diccionario realizado por Nebrija (1495) y, como inmediato avance, el acarreamiento de los materiales lexicográficos de que cada autor dispone con las obras que se van publicando. Así, el siglo XVI y los principios del siglo XVII conforman más de una centuria en la que el español aparece como lengua de trabajo al lado del resto de lenguas importantes del occidente europeo en multitud de obras lexicográficas, bien de tono menor, las llamadas nomenclaturas (Alvar Ezquerra, 1987; Ayala Castro, 1992), bien en forma de diccionarios extensos, tal y como hoy los podríamos entender.

Deberá llegar la fecha de 1611 para que se publique la primera obra lexicográfica monolingüe de español que, aunque fue configurada por su autor Sebastián de Covarrubias, se aproxima bastante a lo que hoy conoceríamos como un diccionario de lengua (Alvar Ezque-

Me gustaría resaltar y agradecer la ayuda de la profesora Leonor Ruiz Gurillo por su apoyo y colaboración en la presentación de este artículo. 
rra, 1976: 14-21), concretamente un diccionario de lengua española ${ }^{2}$. Aunque conocemos la obra de Francisco del Rosal, anterior a ella con licencia de 1601, ésta no llegó a publicarse 3 . Pocos años después, en 1620, verá la luz el Vocabulario italiano-español, español-italiano de Lorenzo Franciosini, el cual obtendrá un éxito editorial de catorce ediciones a lo largo de los siglos XVII y XVIII ${ }^{4}$ y se convertirá, por tanto, en el diccionario de aprendizaje de español para italianos, y de italiano para españoles por excelencia durante todo ese periodo.

Es conocida ya la relación en muchos aspectos de este diccionario italiano-español con el resto de obras lexicográficas que le precedieron. En este sentido, se ha podido comprobar cómo afirmaciones realizadas con anterioridad, tras un estudio detallado, no han resultado válidas, como por ejemplo la copia de Franciosini del Tesoro de Oudin (1607/1616) (Martínez Egido, 2003) o la riqueza de unidades fraseológicas de Franciosini frente al resto de los principales diccionarios publicados desde Nebrija hasta 1620 (Ruiz Gurillo, L. y Martínez Egido J. J., en prensa), fecha de publicación del Vocabulario de Lorenzo Franciosini. En definitiva, es necesario un estudio comparativo y pormenorizado entre todos los diccionarios de la época para establecer con rigor cuál puede ser la deuda, si ésta existiera, de unos hacia otros; finalmente y por extensión, el delimitar la problemática que se encierra detrás del concepto acuñado, y no siempre bien interpretado, de 'fuentes lexicográficas'.

El presente trabajo pretende profundizar en esta idea: configurar la posible deuda del Vocabulario de Franciosini con el Tesoro de Covarrubias en cuanto a la construcción de la microestructura de su segunda parte se refiere (en donde el español es la lengua de entrada), pues es factible pensar que, tal y como demostramos con relación al Vocabulario de la Academia de la Crusca (1612) (Martínez Egido, 2002b) Franciosini pudiera aprovechar la información que un diccionario monolingüe de una lengua con la que trabaja le ofreciera y mostrar, por nuestra parte, a partir de esta composición unas definiciones que resulten válidas y útiles para los diferentes matices englobados dentro del concepto de 'fuente lexicográfica'.

\section{Desarrollo del estudio comparativo}

\subsection{Planteamiento}

Conocemos los datos de la influencia de la macroestructura del Tesoro de Covarrubias en el Vocabulario de Franciosini (Martínez Egido, 2002a: 320-329; Martínez Egido, en prensa), los cuales podrían resumirse en que, del estudio comparativo realizado ${ }^{6}$, hay 1333

2 Vid. Azorín Fernández, D. (2000): Los diccionarios del español en su perspectiva histórica, Universidad de Alicante, Alicante, págs. 97-158.

3 Origen y etymología de todos los vocablos originales de la Lengua Castellana. El manuscrito se encuentra en la Biblioteca Nacional bajo la signatura: ms 6929-T.127. Una parte de ella, la correspondiente al alfabeto primero se encuentra publicado en edición facsimilar: Rosal, F. de, Diccionario etimológico, Gómez Aguado, E., ed. (1992), C.S.I.C, Madrid.

4 Además de la primera de Roma, 1620, hemos constatado: Roma, 1633; Geneva, 1636; Geneva, 1637; Roma, 1638; Venetia, 1645; Venetia, 1665; Venetia, 1666; Genevra, 1706; Genevra, 1707; Venezia, 1735; Venezia, 1763; Venezia, 1774; Venezia, 1776; Venezia, 1796.

5 Las fechas corresponden a las dos primeras ediciones respectivamente.

6 La muestra de comparación consistió en el $10 \%$ de las entradas de la segunda parte del Vocabulario de Franciosini compuesta por 3515 entradas repartidas proporcionalmente entre todas las letras que lo integran. 
entradas compartidas $(37,92 \%)$, mientras que las entradas que aporta Covarrubias y que Franciosini no recoge ascienden a 183 (5,20\%). De este modo, la obra del lexicógrafo español se configura como una fuente directa de la macroestructura del Vocabulario, solamente sobrepasada por los diccionarios de Oudin ${ }^{7}$, con el que comparte $2378(67,65 \%)$ y de Vittori, 2271 (64,60\%); a su vez también hay entradas que recogen estos lexicógrafos y que Franciosini no incluye en su macroestructura, $753(21,42 \%)$ en el caso de Oudin y 568 $(16,15 \%)$ en el de Vittori. Respecto a la obra de F. del Rosal, aunque pueda ser considerada como el antecedente más directo del Tesoro de Covarrubias, no puede ser considerada una fuente directa de Franciosini, pues en la comparación realizada no hay ninguna entrada que compartan en exclusiva.

Como se ve, hemos hablado de fuente directa, término que no debe confundirse con 'copia', ni mucho menos con 'plagio', pues ya señalamos que la tradición lexicográfica se configura, en uno de sus polos, con el acarreamiento de materiales de unas obras respecto a las que las preceden y, en este sentido, aunque haya un número de entradas común, son muy importantes tanto las aportaciones nuevas en la macroestructura que realiza Franciosini, por ejemplo en el número de entradas pluriverbales ${ }^{8}$ que introduce (Martínez Egido, J.J y Ruiz Gurillo, L., en prensa) como las entradas de Covarrubias que no acoge en su obra.

Si la originalidad de un lexicógrafo puede observarse en la configuración de su macroestructura, su verdadero trabajo se puede constatar en la redacción de la microestructura pues, tras el trabajo de selección y configuración de las entradas, vienen la explicación, la selección de información y la traducción que debe ofrecer para que su diccionario sea funcional y válido para los receptores a quienes se dirige. Evidentemente, en este sentido, al tratarse de obras lexicográficas diferentes, pues la una es monolingüe y la otra bilingüe, y con finalidades distintas, las microestructuras de ambas tienen que ser obligatoriamente heterogéneas. Covarrubias concibió su obra como un diccionario etimológico, el cual, en su desarrollo, se va convirtiendo en una obra enciclopédica en la que las informaciones adicionales van cobrando cada vez más importancia y dando como resultado artículos muy extensos. Toda la información que aporta no sigue una estructuración delimitada, sino que se expone de manera anárquica ${ }^{9}$. Seguramente, tal forma de proceder se deba al estilo artesanal que los lexicógrafos empleaban en la confección de sus obras, dependiendo siempre de su propia competencia lingüística y cultural, así como de las fuentes que pudieran manejar.

\subsection{Muestra de estudio y procedimiento}

Para establecer la comparación entre las dos microestructuras, hemos seleccionado una muestra de estudio de forma aleatoria y suficientemente representativa. Así hemos elegido 426 entradas de la segunda parte del Vocabulario de Franciosini repartidas en las letras "B"

\footnotetext{
7 El estudio comparativo se ha realizado sobre la segunda edición, la de 1616, ya que la enriquece notablemente con respecto a la de 1607.

8 Vid. Lépinette, B. (1989): "Contribucion a l'étude du Tesoro de la Lengua Española o Castellana (1611) de Sebastián de Covarrubias", Historiographica Lingüística, XVI-3, págs. 317-342. Esta autora señala la presencia de este tipo de unidades de Covarrubias a Franciosini.

9 Vid. Seco, M. (1987), "El Tesoro de Covarrubias", en Estudios de Lexicografía española, Madrid, Paraninfo, págs. 97-110. Este autor intenta establecer una tipología de los materiales enciclopédicos así como de los diferentes datos lingüisticos que Covarrubias inserta en su obra.
} 
-142: desde babla hasta bancal-, la letra "L" -88: desde La hasta Lagosta-y la letra "T" -196: desde taba hasta tan bueno tan malo- ${ }^{10}$.

Al tratarse de dos obras lexicográficas con concepción y finalidades diferentes, sus microestructuras difieren mucho por lo que su comparación debe hacerse de forma exhaustiva, pues en principio se podría pensar, por lo ya apuntado, que poco o nada podrían tener en común salvo las obviedades de la lengua. Veamos un ejemplo de cómo desarrollan su microestructura en un mismo artículo"

Bagaje: Vocablo castrense; significa todo aquello que es necesario para el servicio del ejército, así de ropas como de vituallas, armas excusadas y máquinas. Díjose 'a vagando', porque la gente que lleva a su cargo el bagaje, no entra en ordenanza de batalla ni se cuenta entre la de pelea; sólo van adunados en el lugar que se les señala entre los escuadrones. Las cosas del bagaje se llaman en latín 'impedimenta, sarcinae'; y las bestias que lo llevan 'clitellaria iumenta'. Con todo lo dicho me parece que el nombre en francés, según lo que dice Horacio Tuscanela en su Diccionario francés: 'La bagaje de gens de guerre, id est, impedimentum'. El italiano llama al bagaje 'bagaglia'. (Maldonado, ed., 1994, pág. 156)

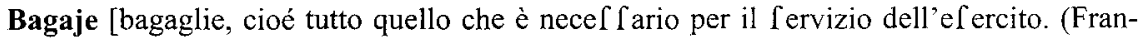
ciosini, 1620 , pág. $90,2^{\mathrm{a}}$ parte)

Pero no ha ocurrido así, ya que con este ejemplo, podemos observar que el Tesoro en alguna de las informaciones que aporta, concretamente en la definición de la entrada, se ve reflejado en la microestructura de Lorenzo Franciosini.

Del número total de la muestra seleccionada en el Vocabulario existen 197 entradas en común con Covarrubias, las cuales no aparecen solamente en la macroestructura del diccionario monolingüe, sino que 52 de ellas las encontramos dentro de la propia microestructura de Covarrubias en la que aparecen definidas o explicadas. Así se confirma la indicación de Alvar Ezquerra (2003: 213) a este respecto: "Las voces que incorpora Franciosini a partir del repertorio de Covarrubias no siempre son las entradas, pues también toma subentradas, y hasta términos que hay en las definiciones".

En este procedimiento encontramos 15 ejemplos en la letra "B", 18 en la letra "L" y 19 en la letra "T". Como ilustración de ellos, mostramos el correspondiente a la entrada bacia, la cual en Covarrubias tiene el siguiente desarrollo:

"Vaso grande, hondo y tendido en que suelen lavar otros vasos y derramar sobre él agua; y assí quieren algunos se aya dicho de vaciar, o hacia," quasi bacchia", por ser de los vasos parte pertenecientes al dios Bacho y a sus sacrificios; y bazín, vaso de contumelia, porque vaciamos en él los excrementos $(2)^{12}$. [...] Quando un lugar es pequeño, y qualquier cosa que se haga en él se divulga por todos los vezinos, dezimos ser bacín de barbero (1), el qual por ser hondo, delgado y de metal sonoro, el menor golpe que se de en una parte dél,

10 Esta misma muestra de estudio fue la que se utilizó para el estudio de la microestructura de la primera parte. Vid. Martinez Egido, J.J. (2003 b). La selección de las entradas se corresponde con la ordenación de la segunda parte del Vocabulario de L. Franciosini.

11 Hemos seleccionado un artículo que tenga una extensión apropiada para esta exposición, pues de todos es sabido que la mayoría de ellos en el Tesoro tienen una extensión mucho mayor.

12 El subrayado y los números entre paréntesis son nuestros e indican la correspondencia entre las informaciones de las dos obras. 
va resonando y haziendo eccos por todo el bazín; y assí fue galana la similitud de bazia y bazín. Dezimos bazinillo (3) y bazinilla (4), bacinico y bacinica (4). Proverbio: "Escupir sangre en bazía de oro", tener con riquezas poco contento (5). Tómase bazinica algunas vezes por la demanda donde se echa la limosna (6)". (Pág. 178)

En el Vocabulario de Franciosini (pág. 89, II) parte de esta información aparece repartida en siete entradas diferentes de su macroestructura con sus correspondientes desarrollos en su microestructura:

- bacia. [bacino da barbieri. (1)

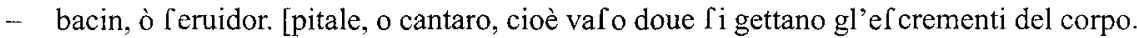
(2)

- bacinillo, o bacinete. [pitaluccio. pitalino. (3)

- bacinete. vedi vacinillo. (-)

- bacinilla, o bacinica. [catinella. catinellina. (4)

- bacinica. [vedi bacinilla. (4)

Escupir fangre enbacia de oro. [Гputar โangue in bacino d'oro. Inferifce, hauer di molte ricchezze, m pochi contenti. (5)

- bacinica. [taluolta fignifica vna fcodella, o fimile $\int$ trumento, doue mettono la limof na di danari, quelli che la domandano per qualche Chiefa. (6)

Este mismo procedimiento lo encontraremos en entradas como bachiller, badajo, badea, bayna, bala, baldios, labor, labrar, ladrillo, ladròn, lagarejo, tauerna, tabla, taco, taja, y tal.

\subsection{Comparación efectiva de las dos microestructuras}

De este modo, la comparación entre ambas microestructuras se vuelve algo complicada pues, a la falta de sistemacidad de la información en la microestructura del Tesoro, debemos añadir este procedimiento que utiliza Franciosini para crear su propia macroestructura: extraer información de la microestructura de Covarrubias.

Para establecer la comparación entre ambas microestructuras, hemos tenido que diseñar un esquema de cotejo ya que, al tratarse de obras tan distintas, no podíamos compararlas uniforme y directamente, pues los comentarios resultantes serían prolijos y, sobre todo, poco operativos. Así hemos diseñado los siguientes parámetros de comparación:

0 . Franciosini sólo ofrece la equivalencia en italiano.

1. Los dos autores ofrecen la misma información y con la misma estructura.

2. La información es muy parecida pero la traducción que ofrece Franciosini de ella sigue una estructura diferente.

3. Franciosini añade información diferente.

4. Ambos autores ofrecen diferente tipo de información añadida.

5. Covarrubias utiliza unos términos pero no los define, mientras que Franciosini los recoge y sí que ofrece información añadida.

Con estas premisas de actuación hemos obtenido los siguientes resultados tras el cotejo de las 197 entradas compartidas de la muestra de ambos autores: 
0. 39 entradas no ofrecen ningún tipo de información añadida ya que Franciosini se limita a dar la equivalencia en italiano.

1. 67 entradas tienen la misma información añadida y siguen la misma estructura en su exposición.

2. 41 entradas presentan una información parecida pero cada lexicógrafo la expone de una forma diferente.

3. No hay ninguna entrada en la que Franciosini sea el que presenta algún añadido sin que se dé ninguna de las demás opciones que estamos analizando.

4. 13 entradas presentan una información añadida diferente en ambas obras.

5. 4 entradas son utilizadas por Covarrubias en su microestructura pero no las define, mientras que Franciosini las incluye en su macroestructura y sí que ofrece información sobre ellas.

El resto de las entradas comparadas presentan una combinación de dos de los rasgos que hemos señalado, así contabilizamos:

- 15 entradas que presentan la combinación 1 y 2.

- 15 entradas que presentan la combinación 1 y 3.

- 2 entradas que presentan la combinación 2 y 4 .

-1 entrada que presenta la combinación 0 y 1 .

A continuación ilustramos tal tipología con algunos ejemplos:

Parámetro $\mathrm{O}$ :

badil. [paletta. (pág. 90, II)

balança. [bilancia. (pág. 91, II)

lacayo. [ [ taffiere. (pág. 459, II)

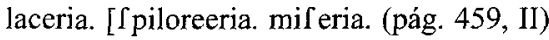

tacaño. [maliziofo. furbo. trincato. (pág. 707, II)

talega. [ [accheta, o facchetto. (pág. 709, II).

Parámetro 1:

\section{COVARRUBIAS (1611)}

BADAJOZ. Ciudad en Estremadura y cabeça de obispo, assentada en las riberas del río Guadiana. (pág. 182) ) $^{13}$

BALANCÍN. Una lança con dos pesos iguales en los cuentos, con la qual los que andan sobre maromas suelen hazer sus entradas para asegurarse, no torciéndose a una parte ni a otra. (pág. 186)

\section{FRANCIOSINI (1620)}

Badajoz.[Città in ef trematura, e capo di Vef couado, alla riua di Guadiana. (pág. 90, II)

balancin. [è vna lancia con due pe $\mathrm{i} i$ eguali, nelli ef tremi d'ef fa, con quale que che vanno a ballare fopra il canapo foglion fare le lor entrate per a $\int\lceil$ icurar $\lceil\lceil i$, non torcendo ne a vna parte, ne all'altra. (pág. 91, Il)

13 Todos los textos del Tesoro extraidos como ejemplos la paginación se corresponden con la edición de la obra de Martín de Riquer (1987). 


\begin{tabular}{|l|l|}
\hline COVARRUBIAS (1611) & FRANCIOSINI (1620) \\
\hline LABRADORA. La aldeana. (pág. 746) & labradora. [contadina, villana. (pág. 459, II) \\
\hline $\begin{array}{l}\text { LACRA. La cosa que en sí es digna de lágri- } \\
\text { mas, por la compassión que hace. (pág. 747) }\end{array}$ & $\begin{array}{l}\text { lacra. [cofa degna di lacrime, o di pianto. } \\
\text { (pàg. 459, II) }\end{array}$ \\
\hline $\begin{array}{l}\text { TALAMO. Es nombre griego, [...], el lugar } \\
\text { eminente, en el aposento adonde los novios } \\
\text { celebran sus bodas y reciben las visitas y } \\
\text { parabienes; significa algunas vezes la cama de } \\
\text { los mesmos novios y la quadra don está. [...]. } \\
\text { (pág. 951) }\end{array}$ & $\begin{array}{l}\text { talamo. [talamo, nome greco, e fignifica il } \\
\text { luogo alto, \&eminente, coue i fpo fi celebrano } \\
\text { alcuna volta fignifica il letto loro, o la f ftanza } \\
\text { doue ftanno. (pág. 709, II) }\end{array}$ \\
\hline $\begin{array}{l}\text { TAMARAS. Los datiles en rama [...]. (pág. } \\
\text { 952) }\end{array}$ & $\begin{array}{l}\text { tamaras. [dattili che fon ancora in fu la rama. } \\
\text { (pág. 710, II) }\end{array}$ \\
\hline
\end{tabular}

Parámetro 2:

\begin{tabular}{|c|c|}
\hline COVARRUBIAS (1611) & FRANCIOSINI (1620) \\
\hline $\begin{array}{l}\text { BABA. [...] El niño llama al agua baba porque } \\
\text { le es fácil pronunciar la } B,[\ldots] \text { (pág. } 175 \text { ) }\end{array}$ & $\begin{array}{l}\text { baba. [bombo. voce del bambino quando do- } \\
\text { manda da bere, o dell'acqua. (pág. } 89, \text { II) }\end{array}$ \\
\hline $\begin{array}{l}\text { BACHILLER. [...] Al que es agudo hablador } \\
\text { y sin fundamento dezimos se bachiller. [...] } \\
\text { (pág. 179) }\end{array}$ & $\begin{array}{l}\text { bachiller. [anche lignifica ciarlone e dicitore } \\
\text { acuto, ma con poco fondamento. (pág. } 89 \text {, II) }\end{array}$ \\
\hline $\begin{array}{l}\text { LABERINTIO. [...] Qualqułera cosa que en } \\
\text { sí es prolixa, intincada y de muchas entradas } \\
\text { y salidas solemos dezir que es un laborintio. } \\
\text { (pág. } 746 \text { ) }\end{array}$ & $\begin{array}{l}\text { laberinto. [laberinto, luogo intrigato, e che hà } \\
\text { diffile l'vfcita. (pág. } 459, \text { II) }\end{array}$ \\
\hline $\begin{array}{l}\text { LADINO. En rigor vale lo mesmo que latino, } \\
\text { [...]. La gente bárbara en España dependió mal } \\
\text { la pureza de la lengua romana, y a los que la } \\
\text { trabajavan y eran elegantes en ella los llama- } \\
\text { ron ladinos. Éstos eran tenidos por discretos y } \\
\text { hombres de mucha razón y cuenta, de donde } \\
\text { resultó dar este nombre a los que son diestros } \\
\text { y solertes en qualquier negocio; al morisco y } \\
\text { a estrangero que aprendió nuestra lengua, con } \\
\text { tanto cuidado que apenas le diferenciamos de } \\
\text { nosotros, también le llamamos ladino. (pág. } \\
747 \text { ) }\end{array}$ & 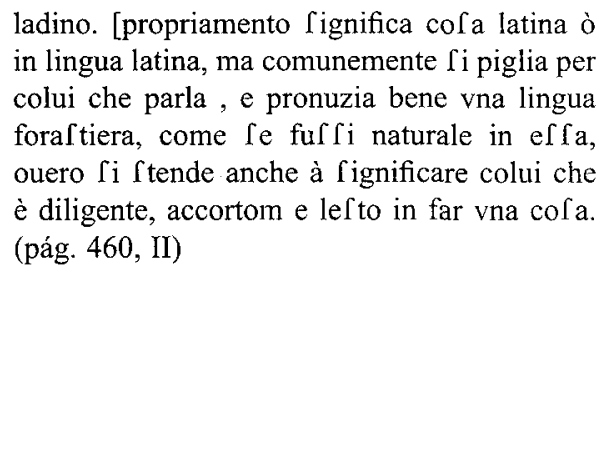 \\
\hline
\end{tabular}




\begin{tabular}{|l|l|}
\hline COVARRUBIAS (1611) & FRANCIOSINI (1620) \\
\hline $\begin{array}{l}\text { TABLAJERO. El señor de la casa que da nay- } \\
\text { pes y dados y lo demás, [...]. (pág. 950) }\end{array}$ & $\begin{array}{l}\text { tablajero. vedi tablagero. [colui che tiene cafa } \\
\text { apeta a giucatori. (pág. 706, II) }\end{array}$ \\
\hline $\begin{array}{l}\text { TAHUR. El que continúa mucho el juego, que } \\
\text { si se repite tahur tahur, dize hurtar, porque } \\
\text { muchos de tahures dan en ladrones quando no } \\
\text { tienen qué jugar. (pág. 951) }\end{array}$ & $\begin{array}{l}\text { tahùr. [vno che fta fempre nelle bifche, giuca- } \\
\text { tore che fempre giuoca. colui che inganna nel } \\
\text { giuoco. marriuolo. (pág. 708, II) }\end{array}$ \\
\hline
\end{tabular}

Parámetro 4:

\begin{tabular}{|c|c|}
\hline COVARRUBIAS (1611) & FRANCIOSINI (1620) \\
\hline $\begin{array}{l}\text { BAYLAR. Lo que en latín llamamos tripudiare } \\
{[\ldots] \text { porque los que bailan se arrojan en alto }} \\
\text { con las cabriolas y se tuercen a un lado ya otro } \\
\text { en las mudanças. (págs. } 184-185 \text { ) }\end{array}$ & $\begin{array}{l}\text { baylar. [ballare, ma non con grauità e rego- } \\
\text { la come s'vfa in certi balli fpagnoli, come } \\
\text { ciaccone, zarauande, follie, perche quando } \Gamma \\
\text { i balla con maeftà \& ordine } \int i \text { dice danzar. } \\
\text { (pág. } 90, \text { II) }\end{array}$ \\
\hline LADERA. La halda del monte. (pág. 747) & $\begin{array}{l}\text { ladèra de cue } \text { ta. [ [ piaggia, o china, ò pendice. } \\
\text { (pág. 459) }\end{array}$ \\
\hline $\begin{array}{l}\text { TAL. [...] Proverbio: "Tal para cual, y Pedro } \\
\text { para Juan. [...]. (pág. 951) }\end{array}$ & $\begin{array}{l}\text { tal para qual. pero para luan. [è vn modo di } \\
\text { dire prouerbiale in I'ignificato di quelche noi } \\
\text { diciamo og'vno fa compagnia co'fuo'pari, } \\
\text { cioè agni fimile appetifce il fuo fimile, e fi } \\
\text { fuol anche dire, tal guaina, tal coltello. (pág. } \\
709 \text {, II) }\end{array}$ \\
\hline
\end{tabular}

Parámetro 5:

\begin{tabular}{|l|l|}
\hline COVARRUBIAS (1611) & FRANCIOSINI (1620) \\
\hline BACÍA. [...] Dezimos bazinillo y bazinilla, & $\begin{array}{l}\text {-bacinillo, o bacinete. [pitaluccio. pitalino. } \\
\text {-bacinete. vedi bacinillo. } \\
\text { bacinico y bazinica [...]. (pág. 178) } \\
\text {-bacinilla, o bazinica. [catinella, catinellina. } \\
\text { (pág. 89, II) }\end{array}$ \\
\hline
\end{tabular}


Parámetro combinación 1 y 2 :

\begin{tabular}{|c|c|}
\hline COVARRUBIAS (1611) & FRANCIOSINI (1620) \\
\hline $\begin{array}{l}\text { BAYNA. [...] Llamamos bainas a las de algu- } \\
\text { nas legumbres por estar encerradas en ellas, y } \\
\text { aun al trigo quando aun no ha echado fuera la } \\
\text { espiga. [...]. (pág. } 185 \text { ) }\end{array}$ & $\begin{array}{l}\text { baynas. [anche } \text { ri chiamano i gu }{ }^{2} \text { ci d'alcuni } \\
\text { legumi, come di faue, fagioli, e baccelli. (pág. } \\
91, \text { II) }\end{array}$ \\
\hline $\begin{array}{l}\text { TALANQUERA. Lugar levantado en alto en } \\
\text { las orillas de las plaças, dende elqual se ven } \\
\text { correr los toros y otras fiestas de plaça; y } \\
\text { porque los que están en ella tienen seguridad, } \\
\text { quando hablan en las faltas que hazen los que } \\
\text { están en el coso, se les responde que hablan de } \\
\text { talanquera. (pág. } 951 \text { ) }\end{array}$ & 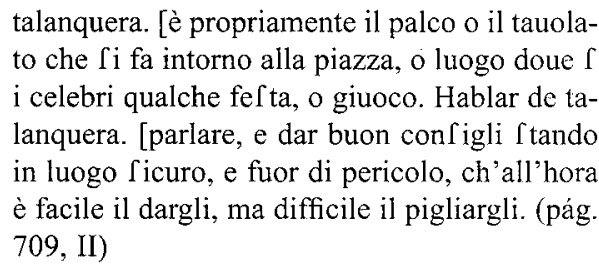 \\
\hline
\end{tabular}

Parámetro combinación 1 y 3 :

\begin{tabular}{|c|c|}
\hline COVARRUBIAS (1611) & FRANCIOSINI (1620) \\
\hline $\begin{array}{l}\text { BABIA. Estar en babia, estar descuydado. } \\
\text { (pág. 175) }\end{array}$ & 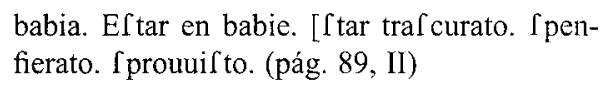 \\
\hline $\begin{array}{l}\text { BABIECA. [...] Al hombre desvaído, grande, } \\
\text { floxo y necio, suelen llamar babieca por el } \\
\text { sonido, con la alusión a bobo. (pág. } 175 \text { ) }\end{array}$ & 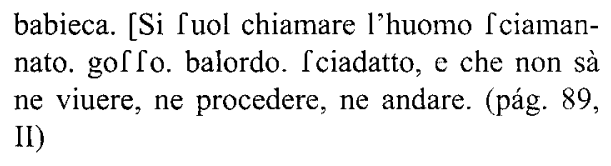 \\
\hline $\begin{array}{l}\text { TALLE. Es la forma que se da a cada cosa, la } \\
\text { qual se perficiona tallando lo supergluo della. } \\
\text { Hombre de buen talle, es lo mesme que gentil- } \\
\text { hombre y agraciado. (pág. } 952 \text { ) }\end{array}$ & $\begin{array}{l}\text { talle. [la forma, \& il garbo che hà ciaf cheduna } \\
\text { cofa. Hombre de buen, o mal talle. [huomo di } \\
\text { bella, o brutta ftatura, cioè di buona, o cattiua } \\
\text { proporzione. No tener talle de hazer cofa bue- } \\
\text { na. [è vn modo di dire, e vale non hauer cera } \\
\text { d'hauer a far cofa che bene Itia. Este Predi } \\
\text { cador lleba talle de no acabar en dos hora. } \\
\text { [Quef to Predicatore hà cera dinon finir di quò } \\
\text { a due hore. (pág. } 710, \text { II) }\end{array}$ \\
\hline
\end{tabular}

Parámetro combinación 2 y 4 :

\begin{tabular}{|c|c|}
\hline COVARRUBIAS (1611) & FRANCIOSINI (1620) \\
\hline $\begin{array}{l}\text { TALABERA DE LA REINA. Villa muy noble } \\
\text { y antigua, [...] .(págs. 951-952) }\end{array}$ & $\begin{array}{l}\text { Talabèra. [nome d'vna terra in Spagna. Platos } \\
\text { de Talabèra. [piatti a maiolica, cioè piatti fatti } \\
\text { con vn lauoro, e inuetriato coSi detto. (pág. } \\
709 \text {, II) }\end{array}$ \\
\hline
\end{tabular}


Parámetro combinación 0 y 1 :

\begin{tabular}{|l|l|}
\hline COVARRUBIAS (1611) & FRANCIOSINI (1620) \\
\hline $\begin{array}{l}\text { TACHA. La falta que se pone a alguna cosa. } \\
\text { [...] Proverbio: No ay mula sin tacha; este ani- } \\
\text { mal, por se hembra y engendrada de diversas }\end{array}$ & $\begin{array}{l}\text { tacha. [taccia. vizio. mancamento. difetto. No } \\
\text { ayula fin tacha. [non fi troua mula fenza } \\
\text { simientes, de ordinario tiene algunos malos } \\
\text { resabios. (pág. 950) }\end{array}$ \\
707, II)
\end{tabular}

Tras el análisis efectuado, y con estos ejemplos ilustrativos, las múltiples coincidencias existentes entre ambas microestructuras resultan evidentes, por lo que ya es factible afirmar que el Tesoro de Covarrubias fue determinante en la realización del Vocabulario de Lorenzo Franciosini.

\subsection{Resultados porcentuales del estudio comparativo}

Tras el análisis realizado, los datos de la muestra comparada nos dicen que, casi siempre, la realización de la microestructura de Franciosini sigue de forma directa, como si de un índice se tratara, la microestructura de Covarrubias. Los datos extraídos e interpretados serían:

- Salvo en las entradas que ofrece sólo la equivalencia al italiano -39 , lo que supone un $19,79 \%$ - encontramos la huella del diccionario español en todo lo que son las informaciones añadidas así como en las perífrasis definitorias.

- El 34,01 \% de las entradas (67) presentan una microestructura que es una traducción al italiano de parte de la información que Covarrubias constata en español. A éstas tendríamos que añadir 31 entradas más -lo que elevaría el porcentaje a 49,74\% de la muestra objeto de estudio- que compartirían este rasgo con otro de los consignados por nosotros. De esta forma, nos encontramos con que la mitad de las entradas comparadas contienen una traducción directa en italiano de la microestructura redactada por Covarrubias en su diccionario de español.

- En el 34,01\% de las entradas (41) Franciosini también sigue a Covarrubias, aunque alterando la traducción que ofrece en italiano, por lo que de esta forma puede expresar su libertad como lexicógrafo. A ellas tendríamos que sumar $17-29,44 \%$ - que comparten dos de los parámetros de comparación.

- 13 entradas que presentan una clara separación de la microestructura de Covarrubias, que suponen un $6,59 \%$. A éstas sólo habría que sumar 2 más que comparten rasgo de comparación, lo que elevaría el porcentaje a 7,61\%. Sería sólo aquí donde radicaría la originalidad de Franciosini con respecto al Tesoro, en cuanto a la inclusión de artículos lexicográficos no compartidos con él.

Todos estos datos expuestos quedan reflejados en el siguiente gráfico: 


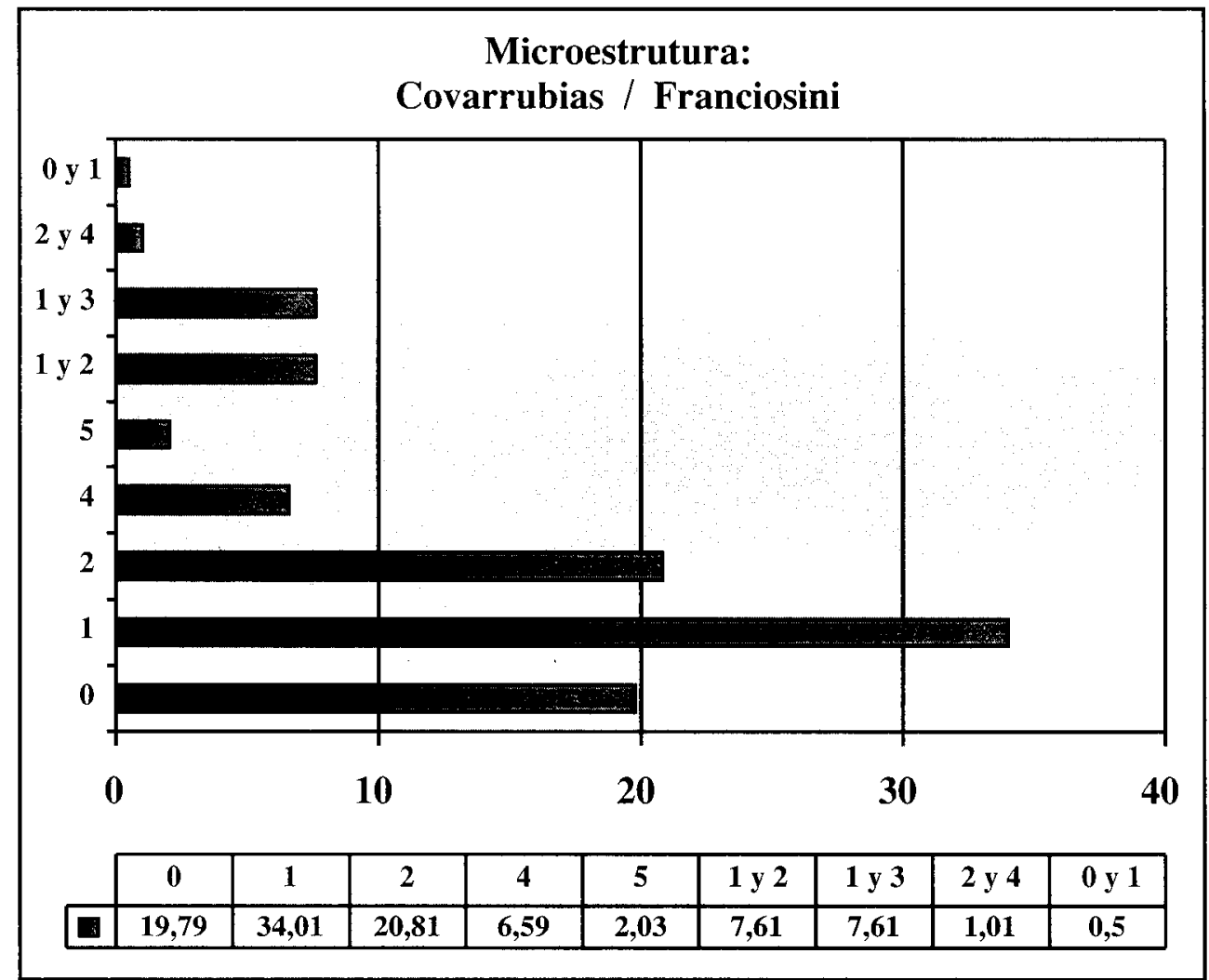

La casuística descrita se distribuye de forma más o menos homogénea a lo largo de las tres letras estudiadas, por lo que, por extensión, los procedimientos que hemos descrito serían los habituales en la construcción de toda la microestructura del Vocabulario, tal y como podemos comprobar en la tabla siguiente:

\begin{tabular}{|l|c|c|c|}
\hline Tipo de micro. & Letra "B" & Letra "L" & Letra "T" \\
\hline 0 & 13 & 16 & 10 \\
\hline 1 & 21 & 15 & 31 \\
\hline 2 & 18 & 10 & 13 \\
\hline 3 & - & - & - \\
\hline 4 & 5 & 2 & 6 \\
\hline 5 & 4 & - & - \\
\hline $1-2$ & 8 & 1 & 6 \\
\hline $1-3$ & 4 & 1 & 9 \\
\hline $2-4$ & 1 & - & 1 \\
\hline $0-1$ & - & - & 1 \\
\hline Total $=\mathbf{1 9 7}$ & $\mathbf{7 4}$ & $\mathbf{4 5}$ & $\mathbf{7 8}$ \\
\hline
\end{tabular}




\section{Conclusiones}

Tras todo nuestro estudio comparativo podemos deducir y afirmar que, sin lugar a dudas, el Tesoro de Covarrubias estuvo plenamente presente en la realización de la microestructura del Vocabulario de Lorenzo Franciosini. Este hecho es perfectamente explicable y lógico por dos motivos: el primero, por el éxito y difusión que tuvo la obra como gran diccionario monolingüe, y el segundo porque, aunque Franciosini tuviera una buena competencia lingüística en español, no podría igualarse a la de Covarrubias, tanto por ser el español su lengua materna como por el interés lingüístico demostrado hacia ella. El lexicógrafo español se convirtió en guía directa para su trabajo sobre la lengua española.

En este sentido, debemos recordar que este procedimiento de creación de la microestructura ya lo constatamos en la primera parte. Alli la obra que se seguía era otro gran diccionario monolingüe de italiano de 1612, el Vocabulario de la Academia de la Crusca (Martínez Egido, 2003b), y aquí, para la segunda parte, el español, sigue con la misma forma de actuación: se centra en otra gran obra monolingüe de la lengua, el Tesoro de Covarrubias. Vemos, pues, que existe cierta homogeneidad en el proceso de recopilación de materiales y de información en las dos partes que constituyen su obra.

La práctica de acarreo de información de unas obras a otras la vemos perfectamente cumplida aquí. El Tesoro es su base y sobre él selecciona, modifica y traduce la información que a él, como lexicógrafo, le parece la idónea para su obra en esta segunda parte, ya que en todos los artículos presenta cierta mesura sobre el original español, no obstante, Franciosini fue un profesor de español que sabía muy bien qué precisaba el alumno que necesitaba o quería aprender español, lo que lo convierte también en un diccionario monolingüe de español para italianos pues, de esta forma, éstos no necesitaban consultar un diccionario de lengua española - por ejemplo, el Tesoro de Covarrubias- ya que podían resolver todas sus dudas con un único diccionario, su Vocabulario italiano-español, español-italiano.

De todo el procedimiento descrito y de los resultados obtenidos, podemos indagar en las diferentes etiquetas que, de forma habitual, se utilizan para hablar y designar a los antecedentes de las obras lexicográficas y ofrecer un intento de definición de ellas, es decir, pensamos que no debe ser suficiente con afirmar que un diccionario bebe de otros anteriores, sino que debe ser necesario precisar cómo es esa relación, ya que, según las diferentes épocas históricas, no siempre las denominaciones se corresponden con el significado que les otorgamos en la actualidad. Por este motivo proponemos las siguientes marcas con sus respectivas definiciones y las aplicamos a casos lexicográficos concretos:

- Plagio: la copia es total, tanto de la macroestructura como de sus correspondientes definiciones y materiales de la microestructura. No se indica que se está copiando y se hace pasar por propia -el conocido plagio de Vittori (1609) hacia Oudin (1607) ${ }^{14}$ -

Copia: se indica que se está copiando un material que no es propio y se declara qué parte es personal si la hubiera -un ejemplo sería el diccionario de Fray Pedro de Alcalá ${ }^{15}-$.

14 Vid. Cooper, L. (1960): "Girolamo Vittori y César Oudin: un caso de plagio mutuo", Nueva Revista de Filologia Hispánica, XIV, 1-2, págs. 3-20.

15 (1505): Vocabulista arauigo en lengua castellana, Granada. El mismo autor indica que utiliza cl Vocabulario de romande en latin, de Nebrija (1495), Salamanca, y que lo traduce al árabe. 
- Fuente: la utilización parcial de una obra para la creación de un diccionario. Aquí se distingue entre:

- Fuente directa: un diccionario sirve de base parcial para la creación de otro -el Vocabulario de romance en latín, 1495, de Nebrija, para la creación de la macroestructura del Vocabulario de Franciosini, el diccionario de la Academia de la Crusca, para la microestructura de la primera parte de este mismo Vocabulario o el Tesoro de Covarrubias, tanto para la macroestructura como la microestructura, del diccionario del lexicógrafo italiano-.

- Fuente indirecta: existen semejanzas entre dos diccionarios, pero son debidas a que ambos han utilizado las mismas fuentes directas -la relación del Vocabulario de Franciosini con el Tesoro de Oudin, 1616-.

- Antecedente: una obra anterior en una misma línea de actuación pero que no es consultada o lo es apenas -el Vocabulario de Las Casas con respecto al Vocabulario de Franciosini (Martínez Egido, J. J., 2002: 304-341, 367-370, 383-392)-.

El trabajo de Lorenzo Franciosini se centra, y aquí está su valor, en darle forma propia y personal a toda la información a la que puede acceder, individualizándola y creando una obra válida y de autor, para así poder ofrecerla al público italiano. Convierte el material monolingüe en bilingüe en perfecta consonancia con el receptor al que va dirigido, y siempre al servicio de la finalidad que pretende conseguir, un diccionario eminentemente práctico, el cual, quizá sin pretenderlo, se convertirá en una gran obra lexicográfica bilingüe de español-italiano.

Según estos argumentos podemos afirmar, sin detrimento para el trabajo del lexicógrafo italiano sino muy al contrario, que el Tesoro de la lengua española o castellana de Sebastián de Covarrubias fue una fuente directa en la construcción de la microestructura de la segunda parte del Vocabulario italiano-español, español-italiano de Lorenzo Franciosini.

\section{Referencias bibliográficas}

Accademici della Crusca (1612): Vocabolario degli Accademici della Crusca, con tre indici delle voci, locuzioni, e prouerbi latini, e greci, posti per entro l'opera, Venecia, Giouanni Alberti.

Alcalá, Fray Pedro de, (1505): Vocabulista arauigo en lengua castellana, Granada.

Alvar Ezquerra, M. (1976): Proyecto de Lexicografia española, Barcelona, Planeta.

Alvar Ezquerra, M. (1987): "Apuntes para la historia de las nomenclaturas del español", en Actas del VII Congreso Asociación de Lingiística y Filología de América latina (ALFAL). Homenaje a Pedro Henríquez Ureña. Santo Domingo, República Dominicana, 1984, Santo Domingo, I, págs. 457-470.

Alvar Ezquerra, M. (2003): “El Vocabulario italiano e spagnolo de Lorenzo Franciosini”, De antiguos y muevos diccionarios del espñañol, Madrid, Arco Libros, págs. 191-220.

Ayala Castro, M. C. (1992): "El concepto de nomenclatura", en Actas del IV Congreso Internacional de EURALEX. Barcelona: Bibliograf, págs. 437-444.

Cooper, L. (1960): "Girolamo Vittori y César Oudin: un caso de plagio mutuo", Nueva Revista de Filología Hispánica, XIV, 1-2, págs. 3-20.

Covarrubias, S. de (1611): Tesoro de la lengua castellana o española, Madrid, 1611. Edición de Riquer, M. De (1987), Alta Fulla, Barcelona. 
Covarrubias, S. de (1611): Tesoro de la lengua castellana o española, Madrid. Maldonado, F. C. R. (ed.), revisada por M. Camarero, (1994), Madrid, Castalia.

Franciosini, L. (1620): Vocabulario español e italiano ahora nuevamente sacado a luz. Roma, Iuan Rufinelli y Angel Manni.

Martínez Egido, J. J. (2002a): La obra lexicográfica de Lorenzo Franciosini: Vocabulario italianoespañol, español-italiano (1620). Alicante, Fundación Biblioteca Virtual Cervantes.

Martínez Egido, J. J. (2002b): "Las fuentes de la microestructura en la primera parte, del Vocabulario italiano-español, español-italiano (1620) de Lorenzo Franciosini”, Estudios de Lingüistica, $n^{\circ} 16$, Universidad de Alicante, Alicante, págs. 289-307.

Martínez Egido, J. J., (en prensa): "El Vocabulario (1620) de Lorenzo Franciosini: realización de su macroestructura" en Actas del I Simposium Internacional de Lexicografia, Barcelona, mayo 2002.

Martínez Egido, J. J. (2003): "El Tesoro de Oudin (1607) y el Vocabulario de Franciosini (1620): dos diccionarios bilingües del español", Alemany, C. et alii (eds.): Con Alonso Zamora Vicente (Actas del Congreso Internacional "La lengua, la Academia, lo popular, los clásicos, los contemporáneos"). Universidad de Alicante, Alicante, vol. II, págs. 817-823.

Martínez Egido, J. J. y Ruiz Gurillo, L. (en prensa): "La integración de la fraseología en los primeros diccionarios del español: el Vocabulario de Lorenzo Franciosini", Actas del VI Congreso Internacional de Historia de la Lengua Española, octubre 2003, Madrid.

Nebrija, A. de, (1495): Vocabulario de romance en latín, Salamanca.

Lépinette, B. (1989): "Contribucion a l'étude du Tesoro de la Lengua Española o Castellana (1611) de Sebastián de Covarrubias", Historiographica Lingiuística, XVI-3, págs. 317-342.

Oudin, C. (1616): Tesoro de las lenguas francesa y española, París, 1616.

Ruiz Gurillo, L. y Martínez Egido, J. J. (en prensa): "Las unidades fraseológicas en el inicio de la lexicografía del español (1495-1620)", Actas del IV Congreso Internacional de Historiografia Lingüistica, octubre 2003, La Laguna, Tenerife.

Seco, M. (1987): "El Tesoro de Covarrubias", en Estudios de Lexicografia española, Madrid, Paraninfo, págs. 97-110.

Vittori, G. (1609): Tesoro de las tres lenguas francesa, española e italiana. Ginebra, Philippe Albert y Alesandre Pernet. 